\title{
FATORES INFECCIOSOS CAUSADORES DE ENCEFALOPATIAS CRÔNICAS DA INFÂNCIA
}

\author{
ANTONIO B. LEFÈVRE *
}

E grande ainda, apesar da abundante literatura acumulada, o desconhecimento quanto aos fatores pré-natais capazes de provocar distúrbios neurológicos. Critérios diversos têm sido usdos para estabelecer correlações determinantes.

O critério retrospectivo, que procura reconhecer fatores patogênicos no passado de um grupo selecionado de doentes, é sujeito às maiores críticas pois exclui, por princípio, todos os indivíduos normais que foram submetidos ao mesmo agente patogênico. Quando dizemos que em determinado grupo de crianças encefalopatas asiladas, uma percentagem $X$ teve sífilis no passado, $\mathrm{Y}$ teve toxoplasmose, $\mathrm{Z}$ teve rubéola ou outra virose, estamos fazendo uma afirmação que pode ser verdadeira, mas não abrange o problema em tôda a sua complexidade, pois continuamos sem saber por que motivo uma criança teve seu sistema nervoso atingido, enquanto outra, que foi submetida ao mesmo agente patogênico e na mesma época, não apresentou encefalopatia.

Por outro lado, o critério prospectivo, por maiores que sejam seus méritos, encontra também obstáculos intransponíveis. Dentro de 10 anos, quando o grande inquérito colaborativo prospectivo norte-americano ${ }^{36}$ estiver terminado, poderemos dizer que conhecemos a responsabilidade da toxoplasmose, diagnosticada na gestante, como fatôr determinante de encefalopatia no produto da gestação? Seguramente não pois não é possível deixar evoluir, sem tratamento, uma doença, para observar o que vai ocorrer no futuro. Da mesma forma êste inquérito não fornecerá conhecimentos seguros sôbre o futuro neurológico dos recém-nascidos que sofreram asfixia perinatal, pois certo número de recursos terapêuticos está sendo empregado para reduzir os efeitos da anóxia e de acidose pós-asfíxica. Em que pesem estas limitaçōes, o método de estudo prospectivo é o que tem a possibilidade de fornecer informações mais seguras. $\mathrm{E}$ bastante lembrar a quantidade de conhecimentos obtidos com o seguimento prospectivo das gestantes contaminadas por rubéola durante a grande epidemia norte-americana de 1964-65.

Os conhecimentos que dispomos sôbre os fatores pré-natais causadores de encefalopatias infantís estão se acumulando em alguns campos isolados.

Relatório apresentado ao IV Congresso Brasileiro de Neurologia (Pôrto Alegre, 5 a 9 de julho de 1970).

* Professor de Neurologia Clinica Infantil na Faculdade de Medicina da Universidade de São Paulo. 
Focalisando o tema sob o ângulo visado neste relatório - fatôres infecciosos pré-natais - podemos afirmar que as encefalopatias decorrentes da rubéola, da toxopalsmose, da varíola, do vírus da citomegalia e da sífilis são hoje bastante conhecidos em muitos de seus aspectos. A neuropediatria brasileira, com o trabalho de G. Machado de Almeida ${ }^{22}$, contribuiu decisivamente para o conhecimento de uma delas, a decorrente de infecção pelo vírus da varíola. Entretanto, o médico prático esbarra ainda com obstáculos para esclarecer a etiologia de muitas encefalopatias. Sirva de comprovação para esta afirmativa, o trabalho apresentado por Ivanainem ${ }^{17}$ no $18 .^{\circ}$ Congresso Escandinávico de Neurologia, em 1967. Este autor procurou estudar a etiologia de 624 casos de encefalopatias infantís crônicas, chegando a conclusão que 255 delas estavam ligadas a fatores pré-natais. Apesar de terem sido autopsiadas 52 destas 255 pacientes, só foi possivel apurar a etiologia em 37 casos, dos quais 20 decorriam de fatores tóxicos, 12 de fatores infecciosos, um de traumatismo físico, sendo 4 conseqüentes a mais de uma causa. Causados por agentes infecciosos foram encontrados 5 casos de sífilis, 3 de toxoplasmose, 2 de rubéola e 2 de infecções não determinadas.

Nāo é possivel falar sôbre fatores pré-natais sem recordar alguns aspectos relacionados com a gestaçāo. $\mathbf{E}$ do conhecimento geral que a vida pré-natal é dividida em dois periodos, o embrionário e o fetal, embora Ballantyne, citado por Benda ${ }^{4}$, destaque a importância de um periodo intermediárjo, o néo-fetal, correspondente ao tempo decorrido entre a $7 .^{\text {a }}$ e a $12 . .^{\text {a }}$ semanas, responsável por grande número de malformações em virtude de modificações que ocorrem, nêste momento na circulação materno-fetal. Lembremos que, grosseiramente, pode-se considerar o período embrionário como morfogênico ou organogenético, ou seja, o período em que se forma a maior parte dos órgãos embora o crescimento do embrião seja tão pequeno que, no final da 8.a semana, ainda mede apenas $25 \mathrm{~mm}$. Se observarmos um embriāo com esta dimensão, causa espanto a verificação de que êle tem sua superficie externa muito semelhante à que vai ter no final da vida fetal. Os dedos da mão e do pé já estão divididos, as orelhas e os olhos já assumiram, aproximadamente, sua situaçāo definitiva. Não obstante, o desenvolvimento do sistema nervoso central ainda é extremamente incipiente, no que diverge muito. dos demais órgãos.

O embriologista, ao procurar descobrir a época em que um agente patogênico atuou, tem que levar em conta a "patologia do desenvolvimento". Sabe-se que o desenvolvimento pode ser interrompido em determinada etapa e que pode haver mesmo a destruição de estruturas já formadas. O que não pode ocorrer é a reversão a etapas já superadas. Estando os dedos do pé e da mão já separados entre a sétima e a oitava semana de vida embrionária, nāo é mais possivel que um agente patogênico atuando nêste momento produza, entre outras conseqüências, a sindactilia. O mesmo pode-se dizer para o hipertelorismo, a ciclopia, os defeitos na situação das orelhas, pois neste momento (8.a semana) a topografia dos olhos e orelhas já é a definitiva. Esta lei do sincronismo é muito importante para que se conheça o momento em que o fatôr patogênico atuou sôbre o embrião, pois, apesar de ser muito curto o periodo morfogênico, êle é de intensa atividade organogenética. Apenas para citar um exemplo, o embrião de 7 semanas, com $17 \mathrm{~mm}$, ainda tem hipertelorismo, sindactilia e a abertura da orelha está situada abaixo da boca. Em uma semana apenas, com o crescimento de $8 \mathrm{~mm}$, processa-se a separação dos dedos e a mudança de posição dos olhos e das orelhas. O conhecimento da embriogenese dos vários órgãos permitirá deduzir o momento, quase exato, em que o virus da rubéola, por exemplo, exerceu sua atividade teratogênica. 
O periodo final da vida pré-natal, o fetal, além de ser aquele em que se dá a maturação funcional dos órgãos, é caracterizado por intenso crescimento, pois se nos primeiros 2 meses o embrião atingiu apenas $25 \mathrm{~mm}$, no final da gestação terá, em média, $50 \mathrm{~cm}$. Neste periodo os órgãos que constituem o sistema nervoso se distinguem dos demais que têm o período morfogênico muito curto, de tal maneira que, no final do sexto mês, o cérebro ainda é muito indiferenciado e a fissuração está apenas começando a modificar a superfície lisa do manto cortícal. A diferenciação do cérebro e da medula prossegue no feto por todo o periodo pré-natal, não estando ainda terminada no momento do nascimento. E por êste motivo que as malformações dos outros órgãos são muito mais raras que as do sistema nervoso. Gilbert Mellin 24, analisando a incidência de malformaçōes nos casos de morte fetal (pêso inferior a $500 \mathrm{~g}$ ) e neo-natal (pêso superior a $500 \mathrm{~g}$ ) encontrou, em 204 casos, 46 malformações dentre as quais 18 correspondendo à morte fetal e 28 à neo-natal. Dentre as 18 mortes fetais foram anotadas 12 malformações do sistema nervoso: anencefalias (6), craniorraquisquises (3), craniosquise (1), hidrocefalia (1) e meningoencefalocele (1). Dentre os 28 casos de morte neo-natal havia 15 malformações do sistema nrvoso, a saber: raquisquises (3), anencefalias (2), hidrocefalias (2), meningomieloceles (2), craniosquise (1), craniorraquisquise (1), escoliose (1), disostose craniofacial (1), cranio-lacunar (1) e malformação de KlippelFeil (1). Se aceitarmos, com Klemetti ${ }^{20}$, que 1 a $3 \%$ das crianças são reconhecidamente malformadas (e que êste número aumenta quando são feitas necrópsias), pode-se imaginar quão grande é o número de malformações do sistema nervoso.

A responsabilidade das infecções no periodo pré-natal como causadoras de malformaçōes do sistema nervoso é reconhecida não apenas pelos estudos prospectivos, como também pode ser sugerida pela distribuição geográfica ou sazonal de algumas malformações. Assim é que Klemetti ${ }^{20}$ relaciona malformações com infecção, destacando o fato de que na Inglaterra foi verificado nítido aumento dos casos de anencefalia nas crianças nascidas no inverno. Por outro lado, Penrose mostrou a grande raridade da anencefalia nos países do leste.

A morte fetal tem sido relacionada com infecções, principalmente a vírus, o que é bastante lógico se atentarmos para a freqüência com que a morte fetal e malformações coesistem. Procuranđo verificar quais os vírus que têm maior ação letal sôbre o feto, Siegel e col. ${ }^{34}$, compararam prospectivamente um grupo de 826 mulheres que tiveram rubéola, sarampo, parotidite, varicela e hepatite durante a gravidez com um grupo contrôle de 826 gestantes sadias, verificando que a rubéola, a hepatite e a parotidite determinavam substancial aumento das mortes fetais, o mesmo não acontecendo com as demais viroses estudadas. A rubéola determina maior número de mortes quando a infecção ocorre no começo da gestação por acometimento direto, enquanto a hepatite atinge mais o feto no final da gestação. Interessante verificação foi a de que a parotidite determina a morte fetal, não por infecção direta, mas em virtude de alterações hormonais e placentárias, o que propõe um outro tipo de patogenia. Tal fato merece maior destaque se recordarmos que os trabalhos mais dignos de crédito afirmam que a parotidite durante a gestação não determina malformações.

Vamos procurar estudar os agentes infecciosos que podem atuar durante a gestação, destacando os mais importantes e que oferecem interêsse prático, 
fazendo apenas referências sumárias àqueles cuja responsabilidade é pequena ou duvidosa. Para ordem da exposição vamos considerar as infecçōes por virus, por toxoplasma, pela sífilis, pela doença de Chagas, por infecções bacterianas e micóticas.

\section{INFECCOES POR VIRUS}

A responsabilidade do vírus da rubéola destaca-se consoante as vultosas referências bibliográficas. A generalidade dos autores salienta a improcedência das análises retrospectivas que trouxeram grande confusão também neste terreno. Em 1950 o Ministério da Saúde Pública na Inglaterra planejou importante investigação ${ }^{18}$ destinada a estudar prospectivamente um grupo de 1681 mulheres que tiveram viroses em diversos períodos da gravidez, comparando com um grupo de contrôle de 5717 gestantes normais. As crianças sobreviventes foram examinadas com 1 a 2 anos de idade. A distribuição das viroses foi a seguinte: rubéola (578 casos); parotidite (501); varicela (298); influenza (168); sarampo (103); poliomielite (33). Em síntese o risco foi calculado para a rubéola, a mais importante das viroses no que diz respeito à capacidade teratogênica, de maneira a permitir um cálculo de "porcentagem", assim exposto: a rubéola materna inciđindo no periodo de gestação, entre 0 a 12 semanas, determinou 5,0\% de abortamentos e 4,5\% de natimortos; entre as crianças que nasceram vivas, 6,9\% faleceram antes dos 2 anos de idade, $13,0 \%$ sobreviveram com graves defeitos e $70 \%$ sobrevivem sem graves defeitos.

Ao fazer o estudo da embriopatia pelo vírus da rubéola veremos que a aceitação dêste grupo rotulado como "sem graves defeitos" em crianças com 1 a 2 anos de idade é sujeito a criticas pois, não raro, o déficit mental se manifesta mais tarde e os distúrbios da audição nem sempre podem ser observados em crianças jovens sem exame apurado. Por outro lado, a existência dêstes $70 \%$ de crianças com potencial bastante favorável traz um sério problema para o clínico ante a indicação do aborto terapêutico nos casos de gestantes com rubéola.

O virus do sarampo também foi considerado capaz de produzir defeitos congênitos pois, nos 103 casos de sarampo, foram encontrados $7,3 \%$ de produtos anormais comparado com 2,3\% no grupo de contrôles. Foi também observado que o sarampo, incidindo nas 12 primeiras semanas de gestação, é mais danoso, embora possa produzir defeitos durante tôda a gestação. A experiência colhida com os 33 casos de poliomielite demonstrou que esta virose é altamente responsável por abortos, natimortos e morte precoce mas não é responsável por malformações. A influenza também mostrou elevada capacidade de produzir a morte nos 2 primeiros anos de vida porém não aumentou o número de malformações de acôrdo com a pesquisa feita na Inglaterra; entretanto, alguns autores, citados por Jackson ${ }^{18}$ afirmam haver um risco maior de anencefalia quando a gestante sofreu a "influenza asiática". A parotidite e a varicela durante a gestação mostraram-se livres de risco. 
Vistos assim êstes dados gerais sôbre os riscos decorrentes das infecções por virus durante a gestação, descreveremos as principais viroses em particular.

Rubéola - É de todas a mais estudada. Os dados colhidos na literatura são controvertidos em vista dos diversos critérios seguidos, bem como de provável variação das sequelas verificadas de uma para outra epidemia. Assim é que, nos 92 casos seguidos por Plotkin e col. ${ }^{30}$, foram encontrados $42 \%$ de pacientes deficientes mentais enquanto que Manson e col. citados por Plotkin e col. ${ }^{30}$, encontraram apenas $10 \%$. Deixemos desde já assinalado que é muito difícil tirar conclusão segura sôbre a real incidência dos defeitos congênitos. Trabalhos comparativos de Forbes ${ }^{14}$ mostraram que as cifras indicativas de incidência de defeitos congênitos variou, entre vários autores, de $15,9 \%$ até $59 \%$.

A epidemia de rubéola de 1964-65 nos Estados Unidos da América do Norte deu margem a numerosos trabalhos prospectivos. O grupo da Johns Hopkins ${ }^{27}$ observou a evolução de 1086 mulheres das quais 613 não tiveram contacto com rubéola durante a gestação, 434 tiveram contacto mas não tiveram sinais clínicos da doença e 39 apresentaram quadro clínico em vários períodos da gestação. Em seu conjunto êste grupo de 39 casos não apenas teve um maior número de mortes e de recém-nascidos com pêso inferior, como o número de malformações congênitas foi significativamente maior (25\%) comparativamente aos dois outros grupos (2,5\%). Estes 39 casos foram analisados separadamente ${ }^{16}$ conforme a rubéola tivesse ocorrido no $1 .^{\circ}, 2 .^{\circ}$ ou $3 .^{\circ}$ trimestre da gestação, sob os pontos de vista clínico e virulógico. O grupo do $1 .^{\circ}$ trimestre constava de 13 gestantes, 7 das quais tiveram filhos considerados normais na época do nascimento sendo que de um dêles foi recolhido o virus da garganta; nos casos das 6 crianças doentes foi recolhido o vírus da garganta e/ou placenta em 3. O grupo do $2 .^{\circ}$ trimestre constou de 19 casos dos quais 4 apresentaram malformações congênitas; de dois dêles foi recolhido o vírus, um da garganta e um da placenta. $O$ grupo do $3 .^{\circ}$ trimestre constou de 5 gestantes que tiveram filhos normais nos quais não foi colhido vírus. Nos 2 casos restantes a rubéola ocorreu no mês que antecedeu a concepção: é importante assinalar que uma das gestantes teve um abôrto espontâneo e a outra um natimorto de $725 \mathrm{~g}$ decois de deslocamento prematuro de placenta. Apesar de serem pequenos êstes grupos em que foram feitos estudos virulógicos, os resultados confirmaram um ponto de vista unânime no que diz respeito à maior responsabilidade da doença ocorrida no primeiro trimestre.

Os resultados obtidos com os trabalhos em que tem sido visado o isolamento do vírus já estão permitindo uma visão mais objetiva do problema. Schiff e col. ${ }^{33}$ observaram um fato surpreendente: o vírus foi recolhido de 14\% (43/300) das crianças nascidas de mulheres expostas a uma epidemia de rubéola durante o primeiro trimestre da gestação; 33 destas 43 crianças virus-positivas não sòmente não tinham qualquer defeito congênito como também durante sua gestação não tinha havido qualquer evidência clínica de 
rubéola na gestante. Deduz-se dai que grande número de casos de rubéola congênita (no sentido laboratorial) pode passar despercebido, se a pesquisa do virus se limitar às crianças nascidas com defeitos congênitos ou às que tenham tido história de rubéola materna. Apenas em 3 dêstes 43 casos havia uma história de rubéola materna durante o primeiro trimestre o que indica que mais de $90 \%$ da rubéola materna foi subclinica nêste grupo. Por outro lado o material de Schiff e col. ${ }^{33}$ (300 casos de Cincinatti e 35 de Dayton) demonstra que a rubéola subclínica é responsável por grande número de defeitos congênitos. Entre 16 crianças que tiveram defeitos congênitos foi recolhido o vírus de 9 . O grande número de infecções subclínicas ${ }^{3}$ está demonstrando que há necessidade de seguimento das gestantes com testes sorológicos ${ }^{31}$. Outra verificação importante é que os recém-nascidos com rubéola congênita podem transmitir a doença para os que se encarregam dos seus cuidados. Embora o número de casos que recebeu gamaglobulina ${ }^{33}$ seja pequeno, êles indicam que os estudos devem ser ampliados pois há indícios de que o medicamento dado na dose de $20 \mathrm{ml}$ pode exercer proteção.

Qual o quadro clínico de rubéola congênita? Qual a incidência de distúrbios do sistema nervoso em comparação com os outros distúrbios que caracterizam o quadro clínico da rubéola congênita? Hardy e col. ${ }^{16}$ estudaram 33 crianças com rubéola congênita tendo isolado o vírus em 21 . A importância dêste trabalho é que foram comparadas as observaçōes feitas no grupo vírus-positivo e vírus-negativo. Apenas 6 dos pacientes vírus-positivos tinham pêso superior a $2.600 \mathrm{~g}$ ao nascer, enquanto que o pêso médio do grupo de vírus-negativo era $2.811 \mathrm{~g}$ Lesão cardiaca estava presente em 16/21 dos vírus-positivo e em $1 / 12$ dos vírus-negativo. Anormalidade ocular foi encontrada em 20 das 33 crianças, sem diferença significativa entre os dois grupos. Distúrbios da audição foram encontrados em 17/33 dos casos, também sem diferença notável. O deficiente crescimento pondero-estatural também foi encontrado em 17/33, sem diferenças entre os dois grupos. Anemia e trombocitopenia foram observados transitòriamente em 8/21 e 1/12. Distúrbios neurológicos foram observados em $7 / 21$ e 1/12, sendo que um dos pacientes apresentou convulsōes incontroláveis aos 3 meses de idade. Pleocitose e hiperproteinorraquia foram observados em 6 casos. Em 4 casos foi obtido o vírus no líquido cefalloraqueano. Microcefalia foi notada em 3 casos sendo que 2 racientes apresentavam retardo psicomotor.

Em grupc de 376 casos, Cooper e col. ${ }^{5}$, notaram os seguintes defeitos: em 252, distúrbios da audição; em 82, doenças cardíacas; em 58, catarata bilateral; em 50, catarata unilateral; em 12, glaucoma; em 147, retinopatias; em 170, retardo psicomotor; em 85, púrpura trombocitopênica. Em 46 casos foi observado típico quadro de paralisia cerebral. Depois de 4 anos de seguimento havia 70 normais e 85 mortos. Lesões ósseas muito semelhantes às da sífilis congênita, que desapareciam com cêrca de 2 meses, foram observadas. A disacusia foi a mais freqüente e pode ser a única manifestação se a rubéola ocorre depois da $8 .^{\mathrm{a}}$ semana, constituindo déficit neuro-sensorial permanente, de severidade variável, podendo ser uni ou bilateral. Dentre 140 casos em que foi estudada, a função vestibular estava alterada em $48 \%$. 
Dentre as manifestações de tipo inflamatório, podemos referir meningencefalite crônica, documentada mediante necrópsias.

Desmond e col. ${ }^{9}$ estudaram detalhadamente os distúrbios neurológicos mostrando que o sistema nervoso central code ser envolvido de várias maneiras e em suas diversas estruturas. $O$ virus interfere no crescimento celular, produz meningites, encefalites, vasculites e retardos da mielinização. Em muitos casos acrescentam-se às malformações os efeitos da anóxia perinatal. Em 81/100 casos seguidos por Desmond e col. foram notados defeitos no sistema nervoso central: letargia, fontanelas abauladas, irritabilidade, distúrbios do sono, pleocitose e hiperproteinorraquia são observados precocemente; distúrbios do sono, irritabilidade e disfagia são mais freqüentes nos primeiros meses; com 18 meses a lista de perturbações é maior (hiperatividade, "falta de parada", convulsões, defeitos na postura, movimentos estéreotipados, hipodesenvolvimento pondero-estadural). O desenvolvimento psicomotor é menor quando há diminuição do perímetro craniano, hipercitose, hiperproteinorraquia e convulsões. No diagnóstico de desenvolvimento de Gesell pioras foram assinaladas à medida que o tempo passava. Com 3 anos o déficit da fala era predominante, sendo atribuível à interferência da disacusia.

Plotkin e col. ${ }^{30}$, estudaram o prognóstico tardio da rubéola congênita observando um grupo de 109 crianças afetadas. Deram ênfase à pesquisa de vírus tardiamente e à titulagem de anticorpos, concluindo que um título superior a $1 / 4$ no teste de neutralização em crianças maiores do que 6 meses é indicativo, em $94 \%$ dos casos, de infecção intrauterina. O vírus foi recolhido do cristalino de crianças até os 18 meses. Sintomas foram encontrados em cêrca de metade dos casos: distúrbios oculares (catarata, glaucoma e coreorretinite) em 53\%, doença cardíaca em $57 \%$, surdez em $51 \%$ e deficiência mental em $42 \%$. Microcefalia foi encontrada em $21 \%$ do total, o que representa $49 \%$ dos casos que apresentaram deficiência mental.

Recentemente tive oportunidade de atender duas crianças, com 7 e 9 meses de idade, com rubéola congênita cuja única sintomatologia era intensa disacusia registrada pela audiometria cortical; o interessante dêstes casos, além do registro precoce de disacusia, é que a mãe de um tinha tido a rubéola no segundo trimestre (como é comum nestes casos oligosintomáticos) enquanto que a outra tinha tido a rubéola no meio do segundo mês de gestação, época em que se instalam graves embriopatias polissintomáticas.

Curiosa observação no que diz respeito ao prognóstico tardio foi feita por Menser e col. ${ }^{25}$ revendo, depois de 25 anos, os primeiros 50 casos bem documentados na Austrália onde, em 1941, Norman Mc Alister Gregg, citado por Forbes ${ }^{14}$, descreveu a síndrome da rubéola congênita. Em 48 casos havia hipoacusia o que, provàvelmente, vem mostrar que êste defeito é muito mais freqüente que o relatado nos trabalhos feitos com crianças pelos métodos tradicionais, nas quais a audição é dificilmente testável; defeitos oculares foram encontrados em 28 casos, deficiência pondero-estatural em 25, defeitos esqueléticos em 20, anormalidades cardio-vasculares em 14 e deficiência mental em 5 apenas, o que revela a diferença de critério com que êste distúrbio tem sido avaliado. Estes 50 pacientes (ainda bastante jovens) tinham tido 8 fi- 
lhos dos quais 7 normais e um, por extraordinária coincidência, portador de rubéola congênita, permitindo ao autor uma série de cogitações sôbre as hipóteses que poderiam explicar o fato de uma mulher que apresentava a síndrome de rubéola congênita ter uma filha com a mesma doença.

Ainda há bastante a se conhecer sôbre a rubéola congênita. Os estudos prosseguem, já tendo sido conseguida a transmissão experimental em macacas grávidas ${ }^{29}$, o que abre campo para a pesquisa de vários fatores que podem interferir no desencadeamento do quadro, particularmente levando em conta os recentes progressos dos recursos laboratoriais ${ }^{31,23}$, que permitem o diagnóstico seguro sem a dispendiosa utilização dos métodos de cultura de vírus.

Citomegalia - A citomegalia, ou doença de inclusāo citomegálica, é extremamente difundida em crianças. Em nosso meio Veronesi, citado por Faria ${ }^{12}$, mostrou que $60 \%$ das crianças da cidade de São Paulo, aos 4 anos de idade, dão demonstração serológica de infecção prévia. Como há uma forma aguda da moléstia que acomete crianças nos 3 primeiros meses de vida, é necessário muito cuidado para firmar o diagnóstico das formas congênitas. Tal como na rubéola, é necessário recorrer aos trabalhos prospectivos para fazer um julgamento seguro sôbre o vírus da doença citomegálica como agente causador de malformações congênitas.

A citomegalia, cujo nome deriva do aumento de volume das células invadidas pelo vírus, é encontrada nas glândulas salivares em $10 \%$ das necrópsias de crianças ${ }^{12}$, sendo que em $1 \%$ das necrópsias é encontrada esta infecção generalizada a vários órgãos. Couvreur ${ }^{6}$ considera que a forma generalizada é encontrada em 1 a $2 \%$ das necrópsias sendo que, em $32 \%$ dos natimortos, pode ser encontrado êste tipo de infecção. A doença é freqüentemente subclínica no adulto e é demonstrada quando se pesquisa deliberadamente o vírus. Feldman ${ }^{13}$ examinou a urina de 185 mulheres grávidas, na primeira consulta em clínica obstétrica, encontrando o vírus em 6 delas. Estas gestantes foram seguidas tendo sido encontrado o virus durante tôda a gestação, no momento do parto e mesmo depois dêste; nenhuma delas teve qualquer manifestação clínica da doença, tendo o vírus sido identificado pela primeira vez entre a $15^{\mathrm{a}}$ e a 26. semana. Dois dos filhos tinham também vírus e todos eram normais sob os pontos de vista clínico geral e neurológico. Estes dados vêm mostrar que a infecção é muito difundida e que, quando ela ocorre durante a gestação, deve ser bem analisada antes de considerar a indução de abôrto terapêutico.

O quadro clínico da doença citomegálica congênita foi estudado por Mc Cracken ${ }^{23}$ que acompanhou longitudinalmente 20 casos, dos quais 2 duvidosamente congênitos pois havia a hipótese de terem recebido o vírus em transfusão de sangue feita no periodo neonatal. Este autor discute a epidemiologia da doença, apresentando cifras tão contraditórias que se conclui pela falta de trabalhos prospectivos com casuística suficientemente numerosa. A manifestação clínica mais freqüente é a hepatoesplenomegalia, encontrada em quase todos os casos, com icterícia não explicada pelas etiologias habituais. A 
sequela mais severa é a encefalite necrotisante. Os 15 sobreviventos do material clínico de Mc Cracken (5 morreram de infecções diversas) foram seguidos até os 5 a 9 anos de idade, sendo encontradas em 7, uma ou mais das seguintes manifestações neurológicas: microcefalia, calcificações cerebrais, retardo mental e problemas de comportamento. Aos 7-8 anos de idade 4 eram normais; os 4 restantes não puderam ser seguidos por tempo suficiente. O autor cita Hanshaw que encontrou comprometimento do sistema nervoso central em 34/42 casos de doença citomegálica. Os estudos clínicos-neurológicos de doença citomegálica mostram muitos aspectos comuns com a rubéola, toxoplasmose e sífilis, embora existam divergências quanto à freqüência dos achados. Assim é que, no material de Mc Cracken, havia apenas um caso com microcefalia e coreorretinite, tão freqüentes na toxoplasmose.

Herpes - Se bem que as manifestaçōes dos herpes neonatal se façam presentes depois de um intervalo livre de 5 a 9 dias, segundo Couvreur ${ }^{6}$, as observações anátomo-patológicas de natimortos mostram que esta infecção pode ocorrer intra-útero indicando a transmissão transplacentária do vírus. Mais de metade dos casos clínicos nascem prematuramente. $\mathrm{O}$ diagnóstico se baseia em: 1) lesões cutâneas eritemato-escamosas sem o aspecto típico das vesículas herpéticas, freqüentemente com infecções secundária; 2) lesōes mucosas (boca, narinas, olhos) graves, de tipo mutilantes; 3) ictericia e síndrome hemorrágica; 4) sinais neurológicos como convulsōes, opistótono, hipotonia e distúrbios da deglutição. A evolução se faz para a morte na maioria dos casos. Os estudos anátomo-patológicos mostram, no sistema nervoso central, lesões de tipo necrótico sem reação inflamatória periférica, sendo encontradas células com inclusões intranucleares acidófilas bastante características. O diagnóstico pré-natal pode ser sugerido pela infecção herpética da gestante ou pela história de herpes recurrente. Há, entretanto, formas clínicas com quadro infeccioso inteiramente inespecífico.

Variola - De grande importância em países subdesenvolvidos onde ainda ocorre como doença endêmica, a varíola é virose fetal sôbre a qual a literatura é muito pobre e incompleta. Em São Paulo, G. Machado de Almeida ${ }^{22}$, embora fazendo a ressalva de que não há trabalhos prospectivos que autorizem uma justa avaliação da responsabilidade do vírus da variola como causador de malformações, descreveu 15 casos de graves encefalopatias. Todas as gestantes tiveram a infecção depois do $1 .^{\circ}$ trimestre, sendo maior a incidência no $7 .^{\circ}$ mês. Houve apenas um parto prematuro. Em 8 crianças doentes foram encontradas cicatrizes de variola no tegumento externo, sendo que uma delas nasceu com lesão cutânea de caráter agudo. O quadro neurológico era o de hidrocefalia com acentuado retardo no desenvolvimento psicomotor. Em 3 casos havia coriorretinite, um tinha microftalmia tendo sido encontrada coriorretinite na necrópsia. O exame de líquido cefalorraqueano mostrou hipercitose em dois casos, o que indicava persistência de processo inflamatório. Foi obtido líquido cefalorraqueano hemorrágico em 4 casos, o que foi atribuído a traumatism de parto. Em todos os casos com menos de 3 meses (6 ao todo) havia hiperproteinorraquia. Foi feita necrópsia de 
dois casos: um permitiu o diagnóstico de encefalite pregressa, havendo hidrocefalia por bloqueio do aqueduto de Silvius, gliose subependimária e calcificaçīes periventriculares; no outro caso também existiam alterações compatíveis como diagnóstico de encefalite pregressa e de provável oclusão do aqueduto de Silvius.

Outros vírus - Têm sido descritos ${ }^{6}$, raramente, quadros de encefalites fetais devidos a vírus da encefalite equina ocidental e da coriomeningite linfocitária. Não foram demonstrados casos de infecção transplacentária pelo vírus coxsackie $B$ ou da encefalomiocardite. O trabalho prospectivo atraz referido feito na Inglaterra ${ }^{18}$ mostrou que a gripe, embora capaz de aumentar consideràvelmente o número de mortes fetais e interrupções da gestação, não aumenta o número de malformações. Delascio ${ }^{7}$ cita pesquisa na qual, ao contrário, foi asinalado "notório aumento de malformações" embora não sejam referidas para o lado do sistema nervoso central. O vírus do sarampo ${ }^{18}$ seria capaz de produzir malformações mas o número de casos é pequeno e não permite conclusões seguras. A vacinação não produz aumento de malformações de acôrdo com autores citados por Delascio ${ }^{7}$, que fizeram observações por ocasião de vacinação em massa (5 milhões de pessoas) realizada em New York. Mac Arthur ${ }^{11}$ pensa de maneira diferente, admitindo que a vacinação contra a varíola, realizada no primeiro trimestre acarreta considerável efeito teratogênico. Assim é que, em 34 mulheres vacinadas neste período de gestação, foi observada a presença de malformações em 16 produtos enquanto que, em 169 mulheres vacinadas a partir do $4 .^{\circ}$ mês, fôra observada anormalidade em apenas 4 crianças. Já referimos ${ }^{19}$ que o vírus da parotidite não acarreta aumento do número de malformações.

$\mathrm{O}$ vírus da hepatite pode produzir infecções transplancentárias, determinando hepatites fetais responsáveis por ictericia neonatal. O seguimento ${ }^{6}$ de 91 gestantes afetadas durante os dois últimos trimestres da gestação mostrou 2 casos de malformação, 2 de morte intrauterina, 3 prematuros e 3 abôrtos. De enorme importância, embora esteja aguardando confirmações de outras procedências, é o trabalho de Stoller e Collman ${ }^{35}$ realizado na Austrália. Êstes autores estudando a incidência anual da síndrome de Down notaram picos periódicos correspondentes aos da hepatite infecciosa. Foram capazes, em 1957, de prever um pico de mongolismo que ocorreu nos anos de 1962 e 1963 com base na epidemiologia da hepatite, inclusive prevendo a distribuição dos casos nas zonas urbana e rural. Levantam a hipótese de serem os cromosomas do óvulo afetados na época da concepção ou mesmo antes.

\section{T O X O P A S M O S E}

Trata-se de uma das parasitoses mais difundidadas sôbre a qual já se acumulou enorme literatura tanto sob os aspectos clinicos como laboratoriais. Miller e col. ${ }^{26}$ admitem que a incidência nos Estados Unidos da América é de 1 para 4.000 nascimentos, ao passo que o trabalho ${ }^{36}$ colaborativo prospectivo norte-americano com base no acompanhamento de 40 mil gestantes não 
selecionadas encontrou incidência mais alta, ou seja, 1 criança afetada para 1.000 ou 2.000 nascidas. Talhamer ${ }^{3 \tau}$ pesquisando a etiologia de encefalopatias infantís crônicas verificou que, em $17 \%$ dos casos, os testes laboratoriais eram sugestivos de toxoplasmose congênita; êste mesmo autor acredita que 6 crianças entre cada 1.000 nascidas na Áustria são afetadas pela toxoplasmose. Estas cifras, discordantes das norte-americanas, são tmbém discordantes das verificadas em outros países da Europa. Éstes números devem ser interpretados com cautela pois a infecção é muito difundida e o diagnóstico não é de notificação compulsória.

O quadro clínico da toxoplasmose congênita é descrito como constituído pela triade sintomática - hidrocefalia, coreorretinite e calcificações intracranianas - embora sejam também encontradas microcefalias e outras alterações oculares. Embora se trate de doença congênita as manifestações clinicas podem aparecer tardiamente, com gravidade tão grande como aquela que se manifesta logo após o nascimento; daí a importância do diagnóstico precoce que permite uma possibilidade de tratamento antes que sequelas irreversiveis possam se instalar.

A toxoplasmose historicamente ligada ao Brasil, graças aos trabalhos pioneiros de Splendore e Magarino Tôrres, tem sido amplamente estudada em São Paulo por Delascio ${ }^{8}$ que publicou, em 1956, alentada monografia e, mais tarde, em colaboração com Veronese ${ }^{k a}$, realizou revisão do quadro clínico, salientando os elementos para o diagnóstico diferencial com a rubéola congênita.

A anatomo-patologia da toxoplasmose congênita tem sido bastante estudada e fornece dados para a interpretaçāo dos quadros clínicos. O toxoplasma tem sido encontrado em qualquer tecido ou órgão, com acentuada predileção pelo sistema nervoso, donde a forma de encefalomielite difusa, frequientemente encontrada na clínica. No tecido nervoso têm sido assinalados granulomas miliares, fócos de necrose, áreas inflamatórias e zonas de calcificação. O caráter necrosante e não supurativo distingue a toxoplasmose da maioria das infeccões que podem atingir o sistema nervoso central. A difusão das lesões deve-se à fácil disseminação hematogênica do parasita.

A freqüência da infeç̧ão pelo toxoplasma é grande; em São Paulo, Nussenzweig, citado por Delascio e Veronese ${ }^{8 a}$, demonstrou $71 \%$ de reações positivas entre 370 doadores de sangue. Os casos de toxoplasmose são relativamente raros se comparados com as enormes cifras atingidas pela infecção. O trabalho prospectivo de Desmonts e col. ${ }^{10}$ trouxe importantes elementos para avaliação numérica, embora não tenha contribuído para o conhecimento da patogenia dos casos clínicos de toxoplasmose congênita. Foram examinadas, no início da gestação, 14.826 mulheres, sendo verificado que $12.404(83,6 \%)$ tinham reações positivas, indicando que já haviam sofrido infecção; as demais $(16,3 \%)$ expostas à infecção durante a gestação foram reexaminadas mais tarde. Foi possivel acompanhar 813 gestantes desprovidas de anti-corpos no $3 .^{\circ}$ mês, sendo verificado que 57 delas vieram a sofrer infecção durante os 6 últimos meses da gestação. Dêstes 57 casos, 21 foram considerados duvidosos, por várias razões, restando 36 casos seguros de infecção durante a gestação. O seguimento destas gestantes mostrou vá- 
rios fatos importantes: 1) não foi notado caso algum de toxoplasmose clinica nas crianças nascidas de mães que sofreram a infecção antes da gestação, sendo assinalado um único caso com diagnóstico laboratorial aos 17 meses de idade, sem, entretanto, apresentar qualquer sinal clínico; 2) foram estudados os produtos de 24 mulheres que adquiriram a toxoplasmose durante a gestação (dois prematuros morreram logo após o nascimento sem que pudessem ser examinados anatomopatològicamente; 12 casos apresentaram anticorpos transmitidos que desapareceram com a idade de 6 a 7 meses; 10 crianças conservaram as reações positivas as quais evoluiram como nos casos de toxoplasmose congênita). Estas 22 crianças eram clìnicamente normais com exceção apenas de uma que apresentou pequena lesão de coreorretinite em um dos olhos.

Este trabalho prospectivo veio confirmar alguns fatos já conhecidos e esclarecer outros. A alta incidência da infecção foi comprovada pela positividade das reações das gestantes no início da gravidez bem como pela verificação de que 8 em cada 1.000 gestantes, nas regiões da França compreendidas nesta pesquisa, são contaminadas pela toxoplasmose durante os 9 meses da gravidez. O acompanhamento destas mulheres demonstrou que a toxoplasmose durante a gestação, na grande maioria dos casos, é uma infecção subclínica que não determina danos no produto da gestação. A afirmação de Talhamer ${ }^{37}$ de que ela é a causa de $17 \%$ dos distúrbios cerebrais congênitos, tem grande importância para o conhecimento da etiologia das encefalopatias congênitas, embora nada informe sôbre a percentagem de mães infectadas que irá ter filhos anormais. Esta pesquisa francesa põe mesmo em cheque as conclusões que se pode tirar de outro trabalho de Talhamer ${ }^{37}$ que propõe a profilaxia da toxoplasmose congênita, fazendo o tratamento das gestantes infectadas durante a gestação. No grupo de 24 mulheres francesas que sofreram esta infecção e não foram tratadas, excluindo-se os dois prematuros que morreram precocemente e não foram necropsiados, pràticamente não foram encontrados sinais clínicos da toxoplasmose congênita.

Apesar destas dúvidas que restam para quem procura estudar a toxoplasmose congênita, esta doença representa, em nosso meio, uma causa importante de encefalopatias infantís. Estamos realizando a revisão de 221 casos de toxoplasmose congênita examinados entre 1962 e 1969 . Esperamos com êste trabalho esclarecer alguns aspectos do quadro clínico e da evolução da toxoplasmose congênita. Não podemos terminar esta excosição sem referir o original registro de Olavo Nery ${ }^{28}$ que relata a observação de duas irmãs, nascidas de gestaçōes diferentes, ambas com indiscutive! quadro clinico de toxoplasmose congênita; êste mesmo autor cita outro registro semelhante, da patologista Aparecida Garcia que observou dois irmãos nascidos de partos sucessivos com diagnóstico de toxoplasmose congênita.

Até há poucos anos a infecção do feto pelo Treponema pallidum era considerada a causa mais importante das encefalopatias infantís. Não vai 
longe a época em que se sugeria, como diagnóstico diferencial entre as possiveis causas de uma encefalopatia crônica da criança, a prova terapêutica com medicamentos antiluéticos: se a criança reagisse bem ao tratamento a sífilis seria a etiologia, se reagisse mal dever-se-ia procurar outra causa. Convém lembrar que para ser firmado o diagnóstico da sífilis os clínicos de então não exigiam provas diretas de infecção. Era bastante que se encontrasse algum quadro "atribuível" à sífilis. Assim é que esta etiologia era considerada a mais importante para a surdez na criança, pois muitas vêzes uma icterícia grave precedia a surdez. Esta icterícia grave, que hoje sabemos estar ligada, principalmente, à incompatibilidade sangüínea materno-fetal e à imaturidade hepática, era cnsiderada então "indicação segura" de sífilis congênita.

Relatório da Organização Mundial de Saúde, referido por Araujo Ramos ${ }^{2}$, chama atenção para o fato de que em 76 paises, sôbre 105 analisados, houve recrudescência da sífilis após um declínio no período 1952-55. No Hospital das Clínicas da FMUSP a incidência da sifilis é relativamente pequena; no perodo de 1955 a 1960 foram registrados 51 casos de sífilis congênita dos quais 3 de neurolues; no periodo de janeiro de 1961 a janeiro de 1970 foram observados 86 casos de sífilis congênita, o que mantém, aproximadamente, a mesma média. A literatura ${ }^{40}$, entretanto, registra o perigo que decorre do "Laid ghost walks". Não nos parece interessante extender êste relatório citando cifras de diversos países que mostram o cuidado com que os diagnósticos são compilados. Em nosso país não há qualquer possibilidade de levantar dados exatos sôbre a incidência de uma doença não denunciada.

Devemos considerar dois tipos de sifilis congênita, a precoce em que as manifestações clínicas se apresentam logo após o nascimento e, a tardia, que se manifesta a partir do segundo ano de vida. A incidência das manifestações neurológicas da sífilis congênita varia muito em função das condiçōes do atendimento de um país para outro. Jeans e Cooke, citados por Ford ${ }^{15}$, encontraram, em 1930, reação de Wassermann positiva no líquido cefalorraqueano de $38 \%$ de crianças brancas com menos de 2 anos de idade nos quais havia evidências clinicas de neurolues. Naquelas com mais de 2 anos a reação de Wassermann no liquor era positiva apenas em $29 \%$ dos casos, porém $16 \%$ tinham sérias lesões do sistema nervoso. Em jovens com sifillis congênita o sistema nervoso é afetado em apenas $5 \%$ dos casos, sendo infreqüente a neurolues assintomática. Êstes mesmos autores afirmam nunca ter visto desenvolver a neurolues em pacientes que tivessem exame de líquido cefalorraqueano normal na primeira infância.

A sifilis congênita precoce se caracteriza por quadro exuberante com lesões cutâneo-mucosas e ósseas típicas e lesões de várias vísceras e do sistema nervoso. Importante verificação foi feita por Jeans e Cooke levando-os a afirmar que o comprometimento do sistema nervoso se manifesta em proporção inversa com o acometimento somático geral pois apenas $11,5 \%$ das crianças com neurolues ativa tem sintomas de sífilis ativa em outros órgãos.

O quadro neurológico da sifilis congênita precoce se caracteriza quase que exclusivamente por meningite, cujo diagnóstico é difícil de ser estabele- 
cido, pois faltam freqüentemente os sinais clínicos que levam a êste diagnóstico nas crianças mais velhas e nos adultos. Segundo Araujo Ramos ${ }^{2}$, excepcionalmente encontra-se abaulamento da fontanela e convulsões; Ford ${ }^{15}$, pelo contrário, cita a ocorrência freqüente de abaulamento da fontanela, rigidez de nuca e convulsões. O diagnóstico é, em geral, feito mediante exame do liquido cefalorraqueano, indicado em vista da sífilis materna. $O$ prognóstico é bom quando a terapêutica é feita precocemente. Se o tratamento não é feito, ou é inadequado, o processo pode se tornar crônico sendo envolvidos vários nervos cranıanos, inclusive o nervo óptico, instalando-se quadro de hipertensão intracraniana e, mesmo, lesões focais em conseqüência de arterites. A hidrocefalia congênita como conseqüência da sífilis é rara; quando ocorre é secundária ao processo inflamatório epêndimo-aracnóideo, manifestando-se, em geral, depois do quarto mês.

A sífilis congênita tardia corresponde, em linhas gerais, à sífilis terciária do adulto, caracterizando-se por lesões gomosas ou parenquimatosas diversas, em geral conseqüentes à meningite. As lesões vasculares podem produzir hemiplegias, epilepsia e retardo psicomotor. Têm sido descritas, mais raramente, formas de tabes e paralisia geral. Quadros de meningomielite também fazem parte do extenso cortejo de sintomas desta grave infecção que pode atingir todo o sistema nervoso central por mais de uma forma de comprometimento. Ainda recentemente observamos, no Pronto Socorro do Hospital das Clínicas da FMUSP, o caso de uma criança de um ano de idade que apresentou sủbitamente um icto cerebral seguido de hemiplegia esquerda total e proporcionada; o exame do líquido cefalorraqueano mostrou discreta hipercitose e positividade das reações de Wassermann e Steinfeld; as reações sorológicas também resultaram positivas sendo, também, comprovada a sífilis materna. O caso evoluiu bem sob o ponto de vista clínico mas o paciente teve alta inalterado quanto à hemiplegia.

\section{DOENCAA DE CHAGAS}

O acometimento do sistema nervoso central pelo Tripanozoma cruzi tem sido objeto de numerosos estudos por parte de pesquisadores brasileiros 1, 21, 38 . Em relatório sôbre os aspectos neurológicos da doença de chagas, Forjaz ${ }^{38}$ discute a possibilidade da infestação do sistema nervoso na vida pré-natal, citando vários autores, inclusive Chagas, que aceitaram esta hipótese para explicar certos casos crônicos cuja fase aguda não era identificada. Expõe Forjaz os argumentos bastante entusiastas daquelas que pretendiam filiar grande número de encefalopatias infantís à doença de Chagas adquirida em situação intrauterina, sendo que Austregésilo chegou mesmo a enumerar 5 tipos de formas neurológicas hoje incluídas dentro do quadro de sindrômico da paralisia cerebral. Forjaz discute criticamente os registros dos casos de encefalopatias infantís atribuíveis — sem documentação segura - a infecção intrauterina pelo tripanozoma, concluindo pela afirmação de que "torna-se, assim, extremamente difícil sair do campo fértil das simples suspeitas diagnósticas e penetrar no terreno sólido das demonstrações convincentes". Lem- 
bra principalmente o fato de que numerosos pesquisadores não têm conseguido demonstrar a presença do tripanozoma no sistema nervoso central de crianças encefalopatas congênitas crônicas, ao contrário daquilo que havia sido referido no passado. Não deixa de ser extranhável tal fato uma vez que o número de indivíduos afetados pela doença de Chagas ainda é muito grande em nosso país e que os meios de comprovação progrediram com o correr dos anos. Veronesi ${ }^{39}$ cita um caso publicado por Jorg, na Argentina, de uma forma mortal de doença de Chagas observada em lactente com 17 dias.

Em nossa experiência clínica não temos um único caso de encefalopatia infantil atribuivel ao $T$. Cruzi. O quadro clínico, pelo que se pode concluir pela revisão da literatura feita por Forjaz ${ }^{38}$ nada tem de peculiar: retardo psicomotor, epilepsia, paralisia espástica, quadros predominantemente extrapiramidais ou cerebelares têm sido observados.

\section{INFECCOES BACTERIANAS E MICOTICAS}

A infecção mais conhecida é a listeriose fetal devida à infecção septicêmica por um bacilo Gram-positivo, difundida por via transplacentária. Trata-se de um quadro extremamente grave com manifestaçōes de meningencefalite, sendo o líquido cefalorraqueano muitas vêzes hemorrágico, com hipercitose onde predominam mononucleares; o germe pode ser encontrado mediante cultura. $\mathrm{O}$ comprometimento multivisceral agrava consideràvelmente a evolução. Um elemento clínico bastante sugestivo para levantar a suspeita diagnóstica é a presença de granulomas faríngeos arredondados, salientes, amarelados. Não raro a infecção é adquirida no momento do parto. Quando o diagnóstico de listeriose é feito durante a gestação o tratamento com sulfamidas, eritromicina, e tetraciclinas tem sido realizado com sucesso, segundo Couvreur ${ }^{6}$. Há, entretanto, formas sub-clinicas na gestante que só se manifestam através da encefalopatia observada futuramente.

Existem outras infecções bacterianas por diversos germes que podemafetar o produto da concepção. Otites e meningites intrauterinas devidas a estreptococos hemolíticos, a estafilococos, a leptospiras a a meningococos podem produzir graves lesões do sistema nervoso central. Tôda a septicemia fetal pode acarretar lesões neurológicas; mesmo que o agente bacteriano das septicemias da gestante não atravesse a placenta, as endotoxinas bacterianas são capazes de produzir lesões diversas como hemorragia, hidrocefalia e necroses do sistema nervoso, como foi demonstrado em estudos experimentais com embriões de galinhas. A imunidade é tanto mais baixa quanto mais cedo se der a infecção. A fraca taxa de gamaglobulina do sistema nervoso fetal explicaria a maior susceptibilidade do mesmo às infecções. Couvreur ${ }^{6}$ sugere que o tratamento de septicemia da gestante deva ser feito sempre com a associação de corticóides, com o que seriam menores as lesões do sistema nervoso fetal.

As fetopatias micóticas são extraordinàriamente raras. Existe a possibilidade de histoplasmose e torulose pré-natais. Não temos qualquer expe- 
riência sôbre êste agente etiológico. O Professor Carlos da Silva Lacaz, em comunicação pessoal, nos informou desconhecer casos em que esteja demonstrada a etiologia micótica de malformações do sistema nervoso.

\section{$R E F E R E N C I A S$}

1. ALENCAR, A. - Alterações cerebelares em pacientes com cardiopatia crónica chagásica. Arq. Neuro-Psiquiat. (Sāo Paulo) 25:191, 1967.

2. ARAUJO RAMOS, J. L. - Sifilis. In Pediatria Básica. Ed. Pedro de Alcantara \& Eduardo Marcondes. Sarvier, São Paulo, 1968.

3. AVERY, G. B.; MONIFF, G. R. G.; SEVER, J. L. \& LEIKIN, S. L. - Rubella syndrome after inaparent maternal illness. Amer. J. Dis. Child. 110:444, 1965.

4. BENDA, C. E. - Developmental Disorders of Mentation and Cerebral Palsies. Grune \& Stratton, New York, 1952.

5. COOPER, L. Z.; ZIRING, P. R.; OKERSE, A. B.; FEDUN, B. A.; KIELY, B. \& KRUGMAN, S. - Rubella clinical manifestations and management. Amer. J. Dias Child. 118:18, 1969.

6. Couvreur, J. - Foetopathies. In Problémes Actuels de Pédiatrie. A. Hottinger \& H. Berger Edit., Basel, 1963.

7. DELASCIO, D. - Fatores etiológicos das ovopatias. Ginecologia e Obstetrícia (São Paulo) 27:59, 1969.

8. DELASCIO, D. - Toxoplasmose congênita: aspectos clínicos, obstétricos e experimentais. Maternidade e Infância (São Paulo) 15:179, 1956.

8a. DELASCIO, D. \& VERONESI, R. - Toxoplasmose. In Doenças Infecciosas e Parasitárias. Ed. R. Veronesi, Guanabara Koogan S. A., Rio de Janeiro, 1962.

9. DESMOND, M. M.; MONTEGOMERY, J. R.; MELNICK, J. L.; COCHRAN, G. G. \& VERNIAUD, W. - Congenital rubella encephalites. Amer. J. Dis. Child. 118:30, 1969.

10. DESMONTS, G.; COUVREUR, J. \& BEN RACHID, M. S. - Le toxoplasme, la mere et l'enfant. Arch. Franc. de Pédiat. 22:1183, 1966.

11. EINCHENWALD, H. F. \& SHINEFIELD, H. R. - Viral infections of the fetus and of the premature and the newborn infant. In Advances in Pediatrics. Vol. 12 Year Book Medical Publishers Inc., U.S.A., 1962.

12. FARIA, J. L. - Citomegalia. In Doenças Infecciosas e Parasitárias. Ed. R. Veronesi, Guanabara Koogan S. A., Rio de Janeiro, 1962.

13. FELDMAN, R. A. - Cytomegalie infection during pregnancy: a prospective study and a report of six cases. Amer. J. Dis. Child. 117:517, 1969.

14. FORBES, J. - Rubella: historical aspects. Amer. J. Dis. Child. 118:5, 1969.

15. FORD, F. R. - Diseases of the Nervous System in Infancy, Childhood and Adolecence. 2. ed. Charles C. Thomas, Springfield (Illinois), 1944.

16. HARDY, J. B.; MONIFF, G. R. G. \& SEVER, J. L. - Studies in congenital rubella: clinical and virologic. Bull. J. Hopkins Hosp. 118:97, 1966.

17. IVANAINEM, M. - Clinico-neurological picturees and etiological aspects of cerebral developmental disorders due to prenatal influences. Acta neurol. scand. supl. 31, 1967.

18. JACKSON, A. D. M. - Infection and congenital abnormalities. Practicioner 191:152, 1963.

19. KATZ, M. - Is there mumps embryopathy? An unanswered question. Clin. Ped. 64:63, 1964.

20. KLEMENTTI, A. - Environmental factors and congenital malformations of the central nervous system. Acta neurol. scand. supl. 31, 1967.

21. KöBERLE, F. - Aspectos neurológicos da moléstia de Chagas. Arq. Neuro-Psiquiat. (Sāo Paulo) 25:159, 1967.

22. MACHADO DE ALMEIDA, G. - Hidrocefalia conseqüente à variola incidindo no periodo fetal. Tese de doutoramento apresentada à FMUSP, São Paulo, 1964. 
23. MC CRACKEN, G. H. - Congenital cytomegalic inclusion disease: a longitudinal study of 20 patients. Amer. J. Dis. Child. 117:522, 1969.

24. MELLIN, G. - Birth Defects. Ed. Morris Fishbein, New York. 1963.

25. MENSER, M. A.; DORMAN, D. C.; KENRICK, K.; PURVIS-SMITH, S. G.; SLIM, R.; DODS, L. \& HARLEY, J. - Congenital rubella: a long term follow-up study. Amer. J. Dis. Child. 118:32, 1969.

26. MILLER, J. M.; SEAMAN, E. \& REMINGTON, J. S. - The clinical spectrum of congenital toxoplasmosis. J. Pediat. 70:714, 1967.

27. MONIFF, G. R. G.; HARDY, J. B. \& SEVER, J. L. - Studies in congenital rubella: epidemologic and virologic. Bull. J. Hopkins Hosp. 118:85, 1966.

28. NERY, O. - Subdesenvolvimento e deficiência mental. Toxoplasmose congēnita. Rev. Bras. Def. Ment. 4:17, 1969.

29. PARKMAN, P. D.; PHILLIPS, P. E. \& MEYER, H. M. - Experimental rubella virus infection in pregment monkeys. Amer. J. Dis. Child. 110:390, 1965.

30. PLOTKIN, S. A.; COCHRAN, W.; LINDQUIST, J. M.; COCHRAN, G.; SCHAFFER, D. B.; SCHEIE, H. G. \& FURUKAWA, T. - Congenital rubella syndrome in late infancy. JAMA 200:435, 1967.

31. RAWLS, W. E.; DEMYTER, J. \& MOLNICK, J. L. - Serologic diagnosis and fetal involvement in maternal rubella. JAMA 203:627, 1968.

32. RUDOLPH, A. J.; YOW, M. D.; PHILliPS, A.; DESMOND, M. M.; BLATTNER, R. J. \& MELNICK, J. L. - Transplacental rubella infection in newly born infants. JAMA 191:843, 1965.

33. SCHIFF, G. M.; SUTHERLAND, J. M.; LIGHT, J. Y. \& BLOOM, L. E. - Studies on congenital rubella. Amer. J. Dis. Chlld 110:441, 1965.

34. SIEGEL, M.; FUERST, H. T. \& PERESS, N. S. - Comparative fetal mortality in maternal virus diseases. A prospective study on rubella measles, mumps, chicken pox and hepatitis. New Engl. Med. J. 274:768, 1966.

35. STOLLER, A. \& COLLMANN, R. D. - Incidence of infective hepatitis followed by Down's syndrome nine months later. Lancet II:1221, 1965.

36. Summary of progess in childhood disorders of brain and nervous system. Research profile n. ${ }^{\circ}$ 11. Publ. U. S. Dep. of Health Education and Welfare, 1965.

37. TALHAMMER, O. - La prévention de la toxoplasmose congénitale: méthode et indication régionale. In Problemes Actuelles de Pédiatrie. A. Hottinger \& H. Berger. Edit., Basel, 1963.

38. VERGUEIRO FORJAZ, S. - Aspectos neurológicos da doença de Chagas: sistema nervoso central. Arq. Neuro-Psiquiat. (São Paulo) 25:175, 1967.

38. VERGUEIRO FORJAZ, S. - Aspectos neurológicos da doença de Chagas: Parasitárias. Ed. R. Veronesi, Guanabara Koogan S. A. Rio de Janeiro, 1962.

40. WOODY, N. C. - A laid ghost walks. J. Ped. 64:63, 1964.

Clinica Neurológica - Faculdade de Medicina da Universidade de Säo Paulo - Caixa Postal 3461 - São Paulo, SP - Brasil. 